\title{
Study on Evaluation of the Level of Enterprises Management and Choice of Business Strategy from Enterprises Annual Financial Statements - Take Alibaba for Example
}

\author{
Yihai Liu ${ }^{1, \uparrow}$, Peiyi She ${ }^{2, *, \dagger}$, Xinyi Wang ${ }^{3, \dagger}$ and Jiaqi Yang ${ }^{4, \dagger}$ \\ ${ }^{1}$ Shanghai University of Finance and Economics, Shanghai, China \\ ${ }^{2}$ Jinan University, Canton, China \\ ${ }^{3}$ University of Illinois at Urbana-Champaign, IL, United States \\ ${ }^{4}$ the Secondary High School attached to Beijing Normal University, Beijing, China \\ *Corresponding author. Email: spy084@stu2018.jnu.edu.cn \\ ${ }^{\top}$ Those authors contributed equally
}

\begin{abstract}
With the fast development of internet technology, new and large scaled e-commerce enterprises that highly integrate internet technology and financial instruments have rapidly developed in recent years. For these e-commerce enterprises, their daily accounting processing and the structure of external financial statements will be significantly different from the financial statements of traditional enterprises. Therefore, how to understand the financial information of e-commerce enterprise statements in shorten time; how to understand its constituent factors and its significance of financial data; and how to understand the business behavior hidden after financial data, all of which have caught the eyes of the majority of the investors and enterprise managers. Under such social circumstances, the paper taking Alibaba as an example, using DuPont analysis method to conduct a detailed data analysis of Alibaba's overall financial situation through the detailed financial analysis of profitability, operation, solvency, and the financial situation of cash flow. By analyzing the financial situation of profitability, operating capacity, solvency, and cash flow in detail and combining the research methods of corporate financial management and strategy, this paper makes an active exploration for studying the current booming e-commerce enterprises. Through research, this paper demonstrates that Alibaba's good profitability, solvency, and cash flow are stable and are a positive phenomenon and example for both potential investors and business managers. At the same time, through the example of the financial statements, this paper also further discusses the weak links in Alibaba's strategic management, and puts forward reasonable suggestions for the development of related industries.
\end{abstract}

Keywords: Alibaba; DuPont analysis; accounting statements, corporate strategy.

\section{INTRODUCTION}

Professor Huang Shizhong pointed out that "the industry classification based on technical characteristics leads to the ambiguity of the industry attributes of innovative enterprises, which causes many puzzles in standard horizontal analysis, and seriously weakens the comparability of financial analysis, but however the industry classification and financial analysis based on business model can solve the confusion of financial analysis from industry attributes, which is helpful to solve the problem of standard and improve comparability." [1]. As the financial model of Internet enterprises is different from that of traditional manufacturing enterprises with more fixed assets and inventory, the diversification strategy of enterprises and the business model of "small front desk, large and medium Taiwan" bring new methods to financial management and analysis. With the rapid development of e-commerce business and the integration of big financial data, Xia Ping and Yang Jiping founded that Alibaba's financial data and big data in $\begin{array}{lllll}2 & 0 & 1 & 5 & \text { [2]. }\end{array}$ Thereafter, the coordination index began to decline and tended to develop smoothly after 2016 . 
Li Yibo, Duan Fang Lin pointed out, in the financial analysis of the actual use period, according to the development status of the enterprise, the enterprise should conduct comprehensive and complete research instead of only concerning financial data [3]. Yang Shu (2020) points out that the quality of financial indicators based on accounting data such as balance sheets will also directly affect the authenticity and accuracy of the estimated results [4]. Li Huan et al. (2016) defined financial risk as to the risk that enterprises cannot repay their debts on time because of unreasonable financial structure and improper financing scale [5]. From the definition of financial risk, it can be seen that financial risk is finally manifested in the financial aspects of enterprise debt burden, liquidity, solvency and so on. It is proved that the financial analysis of the enterprise should be based on the statements combined with the project indicators to study the financial risk more persuasively. The table investigated by Mohamed Mehrabanpur (2020) showed that disclosure quality and financial constraints have no intermediary in the relationship between accounting comparability and cash holding, adopting robust ability tests of alternative indicators of cash holding. The results of the study are supporting [6]. Tae-NyunKim (2014) believes that the impact of cash holding and external financing on investment - cash flow sensitivity is caused by the low internal cash flow level of Finance Limited, and from the perspective of financial conservatism, we can judge the risk outlook and value of corporate [7].

Compared with those previous papers about the company's strategic research and management method evaluation, we choose a set of suitable methods to study e-commerce enterprises in this paper. Using the example of Alibaba company [8], our paper is based on the published financial data of recent years. Using the data analysis from Enterprises Annual Financial Statements, through a more in-depth discussion and analysis, we finally get the conclusion that Alibaba [9], as the sample of a typical and comprehensive e commerce enterprises, the level of enterprises management and choice of business strategy is acceptable and reasonable by the investor. At the same time, another contribution of this paper is to conduct a comprehensive analysis of the perspective of Alibaba 's accounting management, combined with the traditional enterprise analysis system and the infrastructure of Alibaba, to provide appropriate suggestions for Alibaba's s future strategic choice.

\section{DATA AND METHOD}

\subsection{Data}

The source of the original data we have selected is the annual report published by Alibaba at the end of each fiscal year, without any third party's reprocessing and processing of the data. The data samples are from the annual reports of companies from 2016 to 2020. The data we used are mainly from the balance sheet and income statement of the company, which are further analyzed by vertical, horizontal analysis and ratio analysis.

Table 1. The data samples are from the annual reports of companies from 2016 to 2020

\begin{tabular}{|c|c|c|c|c|c|}
\hline Account/Time & 2016 & 2017 & 2018 & 2019 & 2020 \\
\hline Operation Net Income(Billion RMB ) & 56.84 & 80.33 & 125.17 & 150.98 & 180.61 \\
\hline Invest Net Expense(Billion RMB ) & 42.83 & 78.36 & 83.89 & 151.06 & 108.07 \\
\hline Net Financing(Billion RMB) & -15.85 & 32.91 & 20.36 & -7.39 & 70.85 \\
\hline Net Income(Billion RMB) & 71.29 & 41.23 & 61.41 & 80.23 & 140.35 \\
\hline
\end{tabular}

Alibaba Group was founded in 1999 in Hangzhou, China, by 18 people led by Jack Ma. From the beginning, all the founders believed in the Internet's ability to level the playing field, allowing small businesses to expand through innovation and technology and better position to compete in not only domestic but global markets. According to the Fifth Person (2020),“ Alibaba Group simplifies commerce for manufacturers, wholesalers, distributors, traders, retailers and consumers in China and Southeast Asia via its online platforms such as Alibaba, Taobao and T-Mall [10]. They are backed by various infrastructures like Cainiao (its logistics network), Ant Group (its FinTech firm), and Alibaba Cloud (its cloud computing arm). On 24 September 2020, Alibaba has a market capitalization of HK\$5.7 trillion." They aim to help companies transform the way they market, sell and do business, and make them more efficient, providing businesses, brands and others with the technology infrastructure and marketing platform to harness the power of new technologies to engage with their users and customers and operate more efficiently. Alibaba's businesses include core commerce, cloud computing, digital media and entertainment, and innovation. In addition, their nonunited affiliated party, Ant Group, provides payment services and financial services to consumers and merchants on our platform. An ecosystem of consumers, merchants, brands, retailers, third-party service providers, strategic partners and other businesses has been built around the platform and business.

\subsection{Method}


The analysis method adopted in this paper first focuses on the financial statement analysis, which is one or more of the four basic elements of the financial statement analysis. The four elements cover different but interrelated aspects of the financial position or performance.

Ratio analysis is used. Liquidity and efficiencyability to meet short-term obligations and to efficiently generate revenues. Solvency - ability to meet long-term obligations and generate future revenues. Profitabilityability to provide financial rewards to attract and retain financing. Market prospects-ability to generate positive market expectations. Liquidity is the availability of resources to pay short-term cash requirements. It is affected by the timing of cash inflows and outflows, along with prospects for future performance. A lack of liquidity often is linked to lower profitability. To creditors, lack of liquidity can cause delays in collecting payments. Efficiency is how productive a company is in using its assets. Inefficient use of assets can cause liquidity problems. This section covers key ratios used to assess liquidity and efficiency.

This paper then uses the DuPont analysis method. The DuPont Analysis is to comprehensively analyze the financial situation of an enterprise by using the relationship between several major financial ratios. Specifically, it is a classic method used to evaluate the profitability of a company and the return on shareholders' equity and to evaluate the performance of an enterprise from a financial perspective. The basic idea is to decompose the return on equity into multiple financial ratios, which is helpful for in-depth analysis and comparison of the business performance of enterprises. This analytical method was first used by the American DuPont Company, so it was named DuPont Analytical Method.

The relationship of several main financial indicators in DuPont analysis is as follows:

"Return on equity" = net interest rate on assets (net profit/total assets) $\times$ equity multiplier (total assets/total equity capital)

(1) Return on equity is the starting point and core of the whole analysis system. The level of the index reflects the size of investors' net asset profitability. Return on equity is determined by the return on sales, turnover of total assets, and equity multiplier.

Whereas: net interest rate on assets (net profit/total assets) $=$ net interest rate on sales (net profit/total income) $\times$ asset turnover rate (total income/total assets)
(2) "Equity coefficient" indicates the degree of debt of an enterprise. The higher the index, the higher the degree of debt of the enterprise. It is the reciprocal of the ratio of assets to equity.

Return on total assets $=$ (net profit/average total assets) $\times 100 \%$

(3) "Return on total assets" is the product of profit rate on sales and turnover of total assets and is a comprehensive reflection of enterprise sales results and asset operations. It is necessary to increase sales revenue and reduce the amount of capital occupied to improve return on total assets.

"The turnover of total assets" = total revenue/ total asset

"The turnover of total assets" reflects the comprehensive ability of enterprise assets to achieve sales income. When analyzing, it is necessary to analyze whether the structure of enterprise assets is reasonable by integrating sales revenue, that is, the structure ratio relationship between current assets and long-term assets. At the same time, we should also analyze the current assets turnover, inventory turnover, accounts receivable turnover and other relevant asset use efficiency indicators, to find out the exact reasons for the change of total assets turnover.

\section{RESULTS AND DISCUSSION}

We use DuPont analysis method and the financial index analysis method to conduct detailed data analysis on the overall financial position of Alibaba, and explain Alibaba's financial position in detail through four parts: profitability, operating capacity, debt-paying ability and cash flow status. We got the conclusion is that Alibaba's good profitability, stable solvency and cash flowability is a positive phenomenon for potential investors. At the same time, in the period of special changes in financial data, we must be good at finding the truth of data implied through other public information platforms, so as to more objectively evaluate the management level of enterprises and give some good suggestions to the company's strategic choice. Here are the research methods and discussion examples.

\subsection{Profitability analysis}


Compared with 2018 total equity has increased to $61 \%$, which indicated that capital structure is stable. The company's total monetary capital is on the rise from 2018 to 2019, indicating an increase in the company's profitability. In 2018, the company's total monetary funds and its share of total assets had declined compared with the previous trend. The reason is that the impact of industry sales accounts receivable increased during the year, and the other is that the customer's settlement cycle has been extended leading to a decrease in the company's bank deposits.

From Alibaba's income statement, we can see that the company has seen a significant increase in revenue from 2017 to 2019. According to observation, we can see that Alibaba's income from operations has decreased by $18 \%$, while its net income has not decreased but increased significantly. It is interesting to see that net income is not only affected by operating income, but also by investment income and income from the investment of the owners of the company. Therefore, correspondingly, Alibaba's interest and investment income had achieved great growth in 2017-2018, and at the same time, there is also a breakthrough in 20182019.

The decline in the net income structure, is mainly caused by a sharp rise in financial costs. In addition, the increase of investment proportion and off-operating income also have a certain favorable impact on the net profit, total income and net profit structure. Meanwhile, interest and investment income from 2017 - 2018 also achieved huge growth, meaning the company placed more emphasis on increasing investment income to corporate income.

At the same time, interest and investment income have also experienced a great increase since 2017, with the proportion increasing from $17.8 \%$ to $44.0 \%$ and finally to $77.2 \%$. It shows that the company will adjust more focus of income to investment income. In addition, we can find significant increases in interest and investment income for 2017 - 2019, which can also be used to explain why revenue grew. Once the enterprise encounters the main business year, if the sphere of business is diversified, it can bring additional profit income to the enterprise and greatly improve its ability to resist risks.

Profitability index analysis does not refer to the amount of net profit. The analysis index often compares the profit with related items to eliminate the disadvantage of absolute comparison. There are two types of profitability indicators. One is to compare profit with sales revenue, and the other is to combine profit with investment. In 2019, the net income in Alibaba's total income dropped from $25.4 \%$ in 2018 to $21.3 \%$, while the proportion of main business income also suffered a significant decline, which is not good for the company.

\subsection{Cash flow analysis}

\subsubsection{Free Cash Flow Overview}

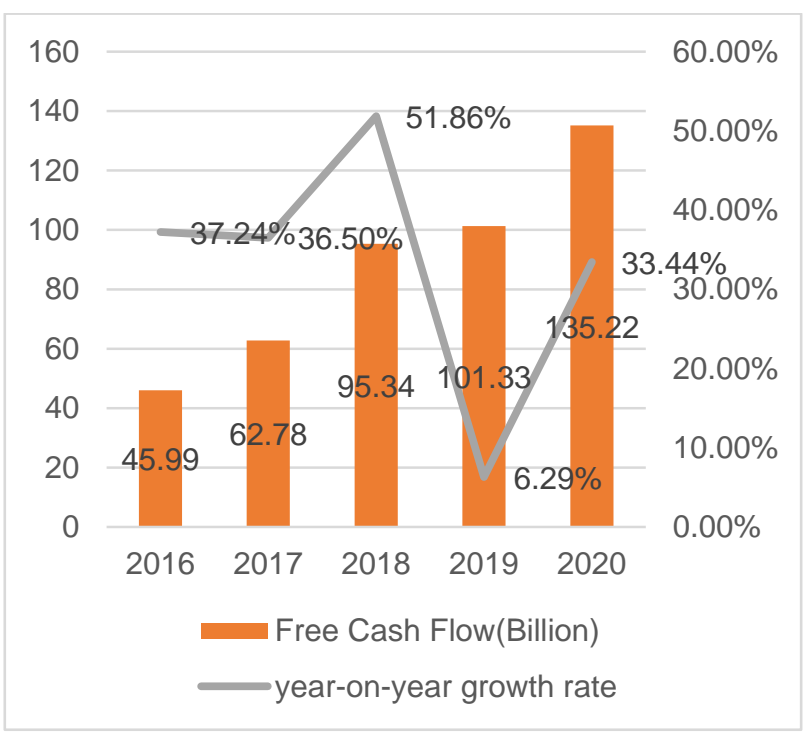

Figure 1. Alibaba Free Cash Flow 2016-2020

Alibaba's cash flow growth rate fell sharply in 2019. According to the income statement, revenue increased 50.58, expenses increased 93.31, and net profit increased 30.65. Visible cash flow changes are mainly due to the increase in 2019 costs. Alibaba expanded its share of investment and financing in 2019, changing the original corporate structure, so it increased costs. The increase in sales income and profit shows that the increase in cash flow is caused by the expansion of market share, which indicates that the growth of enterprises is very good.

In 2018, the company's total monetary funds and its share of total assets had declined compared with the previous trend. The reason is that the impact of industry sales accounts receivable increased during the year, and the other is that the customer's settlement cycle has been extended, leading to a decrease in the company's bank deposits. In the part of profitability, we can find that none of Alibaba's major changes have occurred during these three years, which proves that Alibaba still has stable profitability. And this stability will be a good 
phenomenon for potential investors. It is speculated that the increase in expenses led to the decrease in the proportion of net income and main business income. The booming development of the e-commerce business has produced a good driving effect, improved the utilization efficiency of enterprise assets, and had a positive impact on the performance growth of the company.

\subsubsection{Operations Net Income}

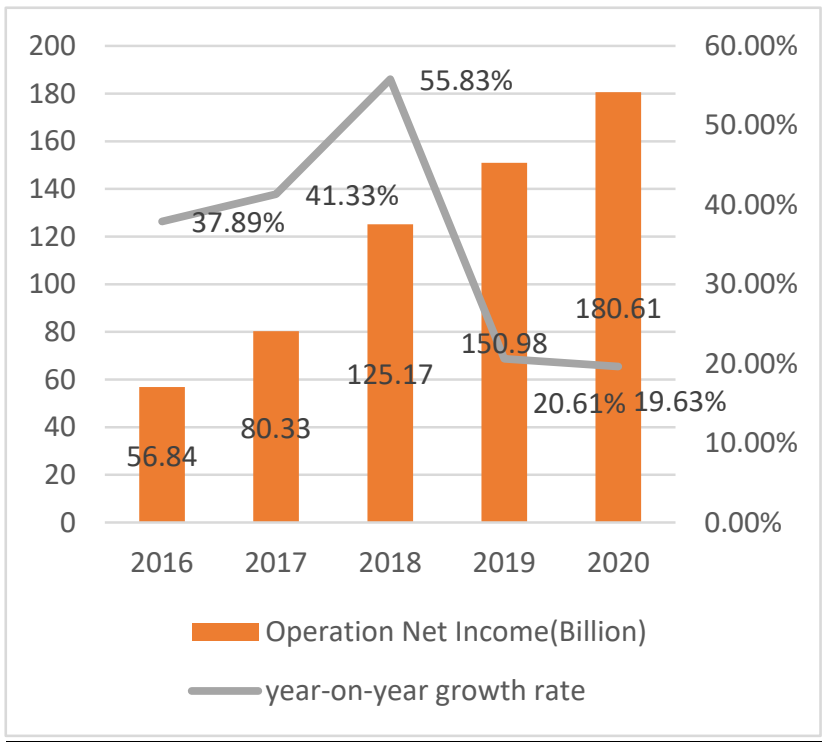

Figure 2. Alibaba Operation Net Income 2016-2020

The cash flow generated by the business activities is positive and maintains a steady growth trend, indicating that the financial management of Alibaba Group is in good condition. Net profit and cash flow from operating activities are close to 2020, and Alibaba Group, as the leader of the Internet industry, has no more depreciation of fixed assets than traditional entity enterprises, so the financial structure is reasonable and the revenue ratio is normal.

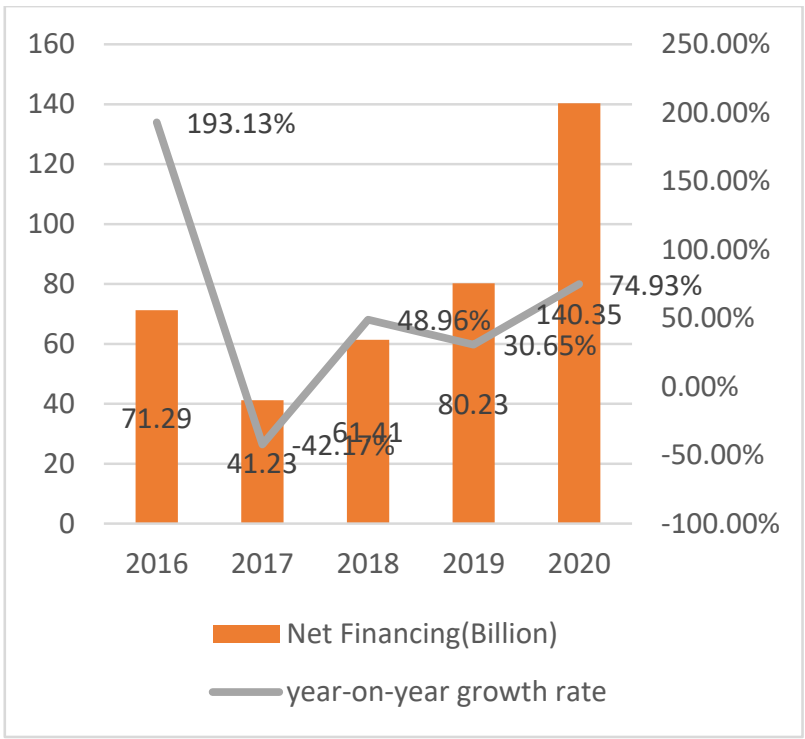

Figure 3. Alibaba Net Income 2016-2020

The turnover days of the company's current assets and total assets continued to decline, and finally dropped to 255 days in 2019 , while the turnover speed of current assets nearly doubled. It can be concluded from the balance sheet that cash and cash equivalents account for the largest proportion of Alibaba's current assets. In 2019, for example, the total amount of current assets was 270.3 billion, among which the total balance of cash and cash equivalents is 190 billion, accounting for about $70 \%$, which also means that the operation and use efficiency of Alibaba's current assets (such as capital) has been greatly improved.

On the one hand, the improvement of total asset turnover efficiency reflects that Alibaba has greatly improved its efficiency in asset management in recent years, and on the other hand, it shows that Alibaba has greatly benefited from the dividends brought by the rapid development of its main business. 


\subsubsection{Invest Net Income}

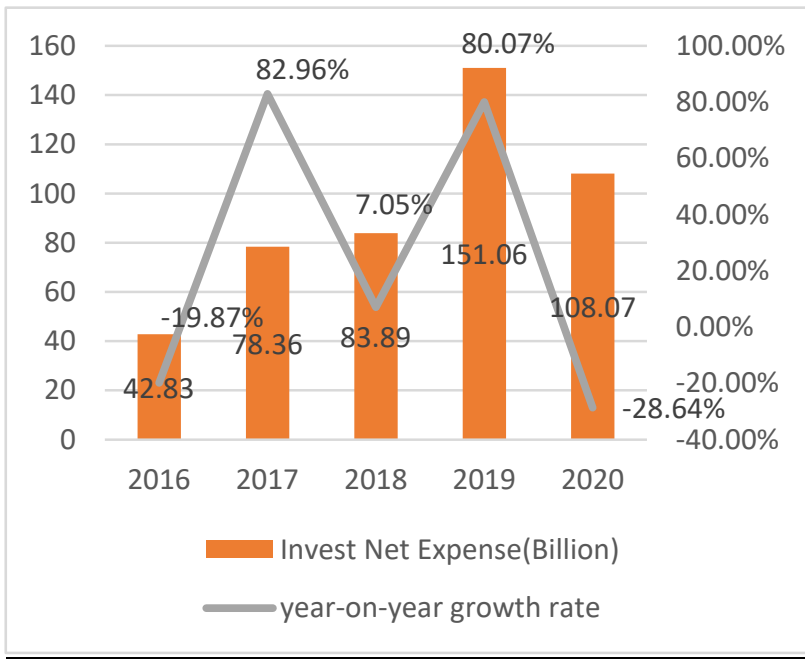

Figure 4. Alibaba Invest Net Income 2016-2020

As can be seen above, Alibaba invested \$15.106 billion in 2019, a year in which high investment also paid off. In 2019, Alibaba invested in 19 companies. Alibaba's Ant Financial Services Group to hungry for two rounds of financing, into long-term equity investment subjects.

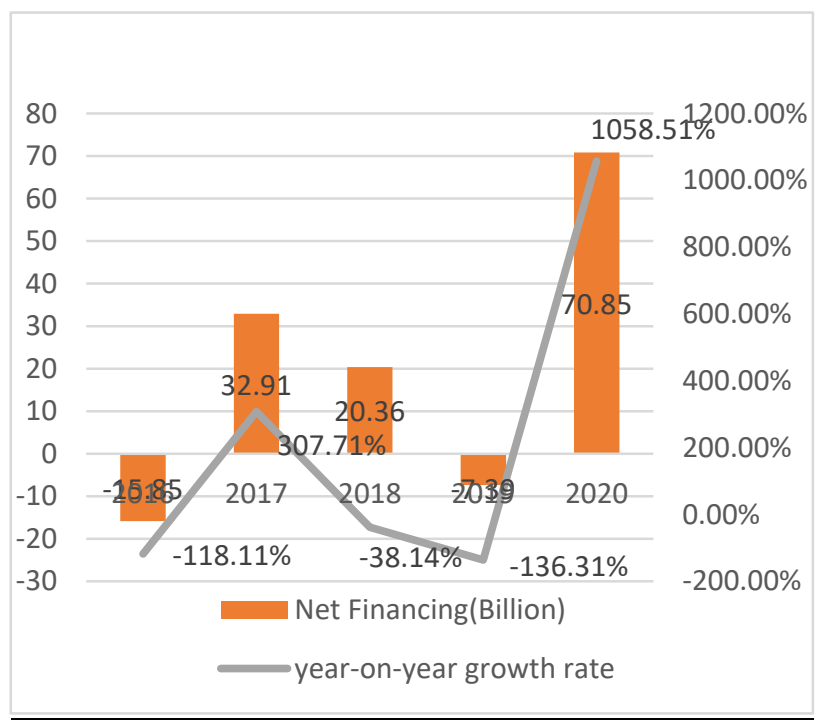

Figure 5. Alibaba Net Financing 2016-2020

Net financing fell sharply to negative in 2019, but rose sharply to positive in 2020, indicating more financing spending in 2019 and more financing revenue in 2020, with Alibaba shares soaring.

Based on DuPont analysis and ratio analysis, this paper analyses the financial situation of Alibaba Group 2016-2020 and draws the trend chart of data change to display financial information intuitively. Alibaba has good operating ability and strong cash flow control ability. In the Internet industry, the overall financial situation is a good and upward trend. It seems that at present, the Alibaba has made great progress in foreign investment and has obtained good enterprise benefits. We hope that Alibaba can broaden its business in terms of investment business, find more development space in other business areas, and become an epoch-making, cross-regional integrated enterprise with e-commerce business as the main business.

\subsection{Growth capacity analysis}

Then we conducted a horizontal analysis of the income statement. During the year 2019, the Group achieved a Net income for the period of RMB 80,234 million and a Net income attributable to ordinary shareholders of RMB 87,600 million, an increase of $48.96 \%$ and $30.65 \%$ respectively compared with 2018 . The increasing trend is favorable for Alibaba.

Also, of the composition of Alibaba's financial results in 2019. The Net income of the Company grew in RMB terms, but the Net income \% dropped over the years. This shows that the cost of the raw materials and goods has increased and is not in line with the increase in sales. It can be seen that the profitability of the company has improved a lot compared with the previous year.

For Ratio Analysis, the ratio data of a single company is difficult to fully illustrate the financial indicators and capabilities of the company. Alibaba's capabilities can only be more intuitively seen through comparison with other companies [11]. For this reason, we choose JD and Amazon to compare with Alibaba. The reason is that the above three companies all take ecommerce platforms as their main business. Meanwhile, JD is Alibaba's main competitor in China, while Amazon is one of Alibaba's main competitors overseas. A horizontal comparison of these three companies can help us judge Alibaba's financial health. 
Table 2. Other company

\begin{tabular}{|c|c|c|c|c|c|c|}
\hline \multirow[b]{2}{*}{ Company } & \multicolumn{4}{|c|}{ Liquidity Ratio } & \multicolumn{2}{|l|}{ Solvency Ratios } \\
\hline & $\begin{array}{l}\text { Current } \\
\text { ratio }\end{array}$ & Quick ratio & $\begin{array}{l}\text { Accounts } \\
\text { receivable }\end{array}$ & $\begin{array}{l}\text { Inventory } \\
\text { turnover }\end{array}$ & $\begin{array}{l}\text { Debt to assets } \\
\text { ratio }\end{array}$ & $\begin{array}{ll}\text { Times interest } \\
\text { earned }\end{array}$ \\
\hline Alibaba(2017) & 1.95 & 1.61 & 56.56 & NA & $36 \%$ & 21.59 \\
\hline Alibaba (2018) & 1.89 & 1.57 & 42.88 & 38.98 & $38.70 \%$ & 23.33 \\
\hline Alibaba (2019) & 1.3 & 1.02 & 6.23 & 31.67 & $36.20 \%$ & 19.65 \\
\hline Amazon (2018) & 2.38 & 0.85 & 15.61 & 8.38 & $73.20 \%$ & 8.95 \\
\hline Amazon (2019) & 1.1 & 0.86 & 14.96 & 8.79 & $72 \%$ & 9.73 \\
\hline$J D(2018)$ & 0.87 & 0.39 & 33.64 & 9.24 & $63 \%$ & 4.78 \\
\hline JD (2019) & 0.99 & 0.48 & 66.69 & 9.65 & $61 \%$ & 19.89 \\
\hline & \multicolumn{6}{|c|}{ Profitability Ratios } \\
\hline Company & $\begin{array}{l}\text { Profit } \\
\text { margin }\end{array}$ & $\begin{array}{l}\text { Asset } \\
\text { turnover }\end{array}$ & $\begin{array}{l}\text { Return on } \\
\text { assets }\end{array}$ & $\begin{array}{l}\text { Return on } \\
\text { common } \\
\text { stockholders' } \\
\text { equity }\end{array}$ & $\begin{array}{l}\text { Earnings per } \\
\text { share }\end{array}$ & $\begin{array}{l}\text { Price earnings } \\
\text { ratio }\end{array}$ \\
\hline Alibaba (2017) & $26 \%$ & 0.36 & $9.50 \%$ & $17.60 \%$ & $\$ 2.55$ & 42.29 \\
\hline Alibaba (2018) & $24.50 \%$ & 0.41 & $10 \%$ & $19.90 \%$ & $\$ 4$ & 45.89 \\
\hline Alibaba (2019) & $21.20 \%$ & 0.44 & $9.50 \%$ & $20.42 \%$ & $\$ 5.06$ & 36.67 \\
\hline Amazon (2018) & $4.30 \%$ & 1.58 & $6.90 \%$ & $28.30 \%$ & $\$ 20.68$ & 72.63 \\
\hline Amazon (2019) & $4.10 \%$ & 1.45 & $6 \%$ & $21.90 \%$ & $\$ 23.46$ & 78.77 \\
\hline $\mathrm{JD}(2018)$ & $-0.60 \%$ & 2.35 & $-1.4 \%$ & $-4.40 \%$ & $(\$ 0.13)$ & NA \\
\hline JD (2019) & $2.10 \%$ & 2.46 & $5 \%$ & $17.80 \%$ & $\$ 0.60$ & 58.71 \\
\hline
\end{tabular}

After comparing the changes of Alibaba itself in the past three years, we will make a comparison with its competitors to further analyze the changes in Alibaba's capabilities. We have conducted a ratio analysis calculation for Alibaba and its competitors Amazon and JD respectively. We originally planned to include the revenue and net income of the three companies in recent years, but considering that the three companies are different in scale, marketing strategy and development period, the comparison of income cannot effectively show the strength and weakness of the various capabilities of the company, so we finally abandoned this part. We're looking at 2019 for comparison.

First of all, although the liquidity of Alibaba is decreasing year by year, the overall liquidity of Alibaba is still higher than that of Amazon and Jindong. It is a very good sign that Alibaba can deliver decent returns for its investors. From the profitability point of view, Alibaba's profitability is very good. In the fierce market competitive environment, Alibaba's profitability is still better than its competitors in the same industry. This suggests that the good development of its main business brings substantial profits to Alibaba.

Finally, solvency analysis, from the perspective of solvency, the solvency of Alibaba industry solvency is at a medium level. Meanwhile, the changes over the last three years have been basically zero, which demonstrates the stability of Alibaba's solvency.

\section{CONCLUSION}

This paper selects Alibaba's financial data in recent years as the research object. Through the research, this paper tries to analyze Alibaba's profitability, operation ability, debt paying ability, and cash flow control ability, and indirectly infer Alibaba's strategic layout and the effect of strategic layout on enterprise value.

This paper sorts out Alibaba's industry background in recent years, analyses Alibaba's competitors in the same industry, and introduces Alibaba's ownership structure and organizational structure. On this basis, 
DuPont analysis method is used to study Alibaba's financial data in recent years. Answers questions about Alibaba's "strategy", "current financial performance", "future development depends on" and so on. Finally, it evaluates the effect of Alibaba's corporate strategy on enterprise value through various indicators. Through our research and investigation, we find that Alibaba has carried out a series of corporate strategy contents with diversified strategy as the primary strategy in recent years, among which other businesses are in the development stage except for the main business. Meanwhile, Alibaba has made a large amount of investment in areas such as cloud service in 2019. Therefore, the business performance of these departments is not outstanding for the time being. However, it can be predicted that, as an emerging industry in the future, there is still a lot of potentials to be explored in the field laid out by Alibaba.

The rapid development of e-commerce industry, cloud and e-commerce as the main business of Internet enterprises in accounting processing and statement accounting and traditional enterprises are very different, how to control the income and expenditure of enterprises, Financing and financing activities to achieve corporate strategic objectives, corporate financial management integrity and effectiveness has become the focus of attention. Therefore, it is very important to study the economic influence of the financial management and industrial and financial integration of the Internet industry.

Alibaba has implemented the diversified strategic layout instead of focusing on the e-commerce industry dominated by Taobao, which has further enhanced Alibaba's ability to resist risks and provided opportunities and possibilities for a series of possible future transformations of the company. We believe that Alibaba should further implement its diversification strategy to ensure the richness of the industry and maintain its leading position in the e-commerce platform Taobao as much as possible, so as to ensure the stability of the capital source for the company's future investment. Therefore, the person in charge of Alibaba needs to think about how to maintain the dominant position of e-commerce platform Taobao in the industry. Only in this way can the diversification strategy of the company be implemented. Otherwise, the diversification strategy will bring a burden to the financial income of the company, and then affect the overall operation of the company
We believe that through the specific financial analysis methods provided by this paper, combined with the strategic management ideas of enterprises, from the perspective of management ability evaluation and investment decisions, we provide a convenient, comprehensive and practical analysis method of e commerce enterprises, which has a good guiding significance to explore other e - commerce enterprises, or new enterprises that may appear in the future.

\section{REFERENCES}

[1] Huang Shizhong. Conffusion and Resolution of Innovative Enterprise Financial Analysis Take Ant Group [J]. Accounting Monthly, 2020, (19): 3-8

[2] Xiping, Yang Jiping. Collaborative Evaluation of Financial Data and Big Data in E-commerce Industry [J]. Accounting Monthly, 2020, (9): 27-34

[3] Li Yibo, Duan Fang. Problems in Financial Analysis [J]. New Business Weekly, 2020, (2): 110

[4] Yang Shu. Change of financial stability status and macroeconomic effect of Chinese listed enterprises [J]. Social Sciences Research, 2021 (2): 115-124

[5] Li Huan, Guo Hongyuan, Deng Jie. The Impact of Financial Risk on Chinese Corporate Credit Risk (above) [J]. Financial Accounting, 2016 (5): 25-32

[6] Mehrabanpour, M., Faraji, O., Sajadpour, R. and Alipour, M. (2020), "Financial statement comparability and cash holdings: the mediating role of disclosure quality and financing constraints", Journal of Financial Reporting and Accounting, Vol. 18 No. 3, pp. 615-637. https://doi.org/10.1108/JFRA-12-2019-0167

[7] Kim, T.-N. (2014), "The impact of cash holdings and external financing on investment-cash flow sensitivity", Review of Accounting and Finance, Vol. 13 No. 3, pp. 251-273. https://doi.org/10.1108/RAF-09-2012-0080

[8] Li Jiahua. Enterprise Competitive Strategy Research in Platform Background takes Alibaba for example [J]. Modern Business, 2020 (02): 15-16

[9] Xu Dongsheng, and Liu Jiaqi. —— takes Alibaba Group as an example [J]. National circulation economy, 2020 (24): 21-23 
[10] Miao. Collaborative effect of enterprise diversification strategy and organizational structure [D]. Hefei University of Technology, 2018

[11] Liu Pengxing. Analysis of Financial Strategy Management in Enterprise Strategy Management Application [J]. Science and Economics, 2019,27 (24): $195+200$ 